\title{
o caminho circular de menina e moÇA
}

\author{
EDSON ROSA DA SILVA
}

\section{INTRODUÇAOO}

Após a leitura do estudo de Helder Macedo sobre o significado oculto da novela de Bernardim Ribeiro( ${ }^{1}$ ), a releitura de Menina e moça se impõe. Muito se esclarece então, e um novo texto - inesgotável, pois isso é próprio da obra de arte - convida-nos a novas descobertas. Lançamo-nos a ele. Não para possiveis descobertas, mas pera saborear tudo aquilo que antes se desconhecia.

A análise de He!der Macedo revela, em toda a obra de Bernaidim Ribeiro, a presença de uma doutrina gnóstica que, para fugir ao fogo da inquisição, acentuou ainda mais seu caráter esotérico. Aponta, com clareza, caracierísticas fundamentais comuns às religiōes gnósticas: na poesia, "a radical divisão do eu em duas partes opostas (Entre mim mesmo e mim), a súbita consciência de uma situação existencial negativa só redimível com a morte (Jano e Franco), a revelação da escuridão circundante como o maior bem possível na terra (Ao longo da Ribeira); a dualística oposição entre a vontade libertadora e a terra aprisionante (Sextina)". E, na Menina e moça, que interessa mais direfamente a este estudo, "além do caráter revelatório e transmundano do amor inspirado por quem 'guarda verdade desconhecida" ", aponta ainda "a insistência na condição de exílio, a definição do bem e do mal como forças opostas numa anormal coexistência, e a coracterização de Deus e da relação que pode unir os homens a Deus em termos de conhecimento, ou gnose" $\left.{ }^{2}\right)$.

Pareceu-nos interessante, e assím se delineia o propósito desta

I MACEDO, Helder. Do significado ceulto da Monina - Moça. Lisboa, Mordes, 1977.

2 Op. cit., p. $39-40$ 
análise, buscá dentro da estrutura do imaginário as imagens que determinam o movimento fundamental do texto que é o da descida, o do retorno. Nos elementos que o autor do Significado oculito da Monina e moça enumera como sendo características de um pensamento gnóstico, "a saudade pela morada original" - o deseịo portanto de "liberar-se da matéria aprisionante e regressar à terra natal" $\left({ }^{3}\right)$ - traduz o sentido de uma iniciação religiosa. O estudo das imagens de Menina e moça, a partir da teoria de Gilbert Durand em Les Structu. res anthropologiques de l'imaginaire, poderá confirmar o propósito do livro: o relato de uma iniciação que, através do sofitimento, levou a Menina a renascer para a outra Vida.

\section{O EXILIO: UM RITUAL DE PURIFICAÇÃO}

\subsection{A prova sacrificial}

"Menina e moça me levaram de casa de minha mãe para muiro longe". Eis que as primeiras linhas do relato da Menina introduzem - tema do desterro que ganha assim uma posição de importância centro do próprio texto. É uma coerência da narrativa pois é pelo ciesterro que se inicia 0 processo de iniciação. Todos os personagens partilham a mesma condição de exilados, o que os faz solidários na mesma dor. Por outro làdo, a identidade das diversas estórias tem af o seu fundamento estrutural. isso equivale a dizer que os personagens de Menina e moça acham-se lançados numa terra estranha, para, através do sofrimento e da purificação, aceder ao conhecimento da verdade, podendo assim retornar à terra-mão.

Hans Jonas, conforme a citação de Helder Macedo( $\left.{ }^{4}\right)$. afirma ser "a relação entre Deus e o mundo e, correspondentemente entre o homem e o mundo" o ponto crucial da doutrina gnóstica:

A divindade é absolutamente transmundana, sendo a sua natureza alheia à do universo, que não criou nem gover na e do qual é a antítese. Ao reino divino da luz, autosuficiente e remoto. é oposto o cosmos, como o reino da escuridãs. $O$ mundo é a obra de poderes inferiores que, embora possam ser imediatamente derivados de Deus, não conhecem o Deus verdadeiro, e obstruem o Seu co. nhesimen:0 ao cosmos que governam.

E assim que vemos o universo de Menina e moça. Numa cons-

3 Ibidem, p. 39

4 lbidem, p. 38 
tante oposição ao mundo material, os pe:sonagens buscam incessantemente uma outra dimensão, aquela que foge à atração terrestre. $O$ exilio é o caminho da depuração, do despojamento das amarras físicas para o regresso à terra natal. Como bem mostra o excelente estudo de $H$. Macedo, o relato da Menına é feito da perspectiva das sombras, uma vez que a narradora iá atingiu a dimensão espiritual. Mas o início da narrativa coincide com o desterro que ainda é a busca da Verdade. A iniciação contém assim a idéia de re-nascimenio.

Ao analisa: o ritmo cósmico, Gilbert Duiant $\left({ }^{5}\right)$ chama a nossa atenção para um grupo de imagens que reuniria o ciclo lunar e o ciclo agrário através das imagens de fecundidade e de maternidade. Em cutras palavras, o simbolismo vegetal é tomado como exemplo de metamorfose pois, nos sacrificios agrários, do corpo sacrificado nasce fieqüentemen:e uma árvore, reativando o processo cíciclo. O diama agro-lunar constriui-se, portanto, pela oposição morte-vida que gera um novo filho capaz de prosseguir o ritmo cósmico. As cerimônias iniciáticas aí se enquadiam e confirmam o ciclo dramático do tempo kois são responsáveis por um homem novo: "l'initia:ion est plus qu'une purification baptismale, elle est transmutation d'un destin"( $(6)$.

Menina e moça é escrito sob o signo da mudança, que é, na realidade, um compromisso com a própria iniciação. Disso tem consciência a Menina:

Daqui me veio a mim parecer que esta mudança em que me eu agora vejo, iá a eu eniāo começava a buscar, quando me esta teria, onde me ela aconteceu, aprouve mais que outra nenhuma, para ir nela acabar os poucos dias de vida que eu cuidei que me sobejavam.(7)

A "mudança" ("transmutation d'un destin"), que no presente da escritura já se operara, é o resultado do exilio donde a idéia de morte - libertação - não está ausente: al vie:a a Menina passar os poucos dias de vida que the restavam( $\left.{ }^{8}\right)$. O exílio surge como um lugar

5 DURAND, Gilberto. Les structures anthropologiques de l'imaginaire. Paris, BordEs, 1980. p. 339.340.

6 Ibidem, p. 351.

7 RIBEIRO, Bernordim. Menina e moça. Publicações Europa-Améried, 1975. p. 25. Adotamos a partir de agora a sigla MM.

3 Ourros passos da noveía revelam essa consciéncia da morte próxima. Vaja-se a esse respeilo o rápido histórico que a menina faz de si mesma para a Dama do tempo antigo: "Fui uma donzela que, neste monte da banda de além deste sibeiro pouco hó que vivo, e näo posso viver muito". Os grifos sūo nossos. 
aparlado do mundo, onde se vem buscar uma "mudança". Trata-se de um isolamento que leva a um aprofundamento de si mesmo, portanto à busca de uma revelação para a qual se faz mister uma iluminação espiritual. Eis porque também a Dama do Tempo Antigo recolheu-se aquele vale:

E assim há já muitos anos que eu não vivo para mim, e que vim para estes ermos, fugindo das gentes para quem só anoiteceu e amanheceu $\left({ }^{\circ}\right)$.

Lamentor, Belisa e Aónia deixam igua!mente a própria terra e, juntos, "de reinos estrangeiros" $\left({ }^{10}\right)$, vêm aportar àquelas partes. Arima que, desde o inicio, é descrita como "a mais formosa cousa do mundo "(11) simboliza uma perfeição inatingivel e parece destinada a uma missão sobrenatural. No seu nascimento está presente a desventura que sela o caráter divino de seu percurso no mundo. Nascendo da morte de sua mãe, numa repetição perfeita do ciclo cósmico, ela é a única que vem à luz em desterro. Avalor, amigo de Lamentor, também é oriundo de outras rerras.

Toda a cerimônia de iniciaçäo repete o mito cíclico que, ao gerar um homem novo, domestica o próprio Tempo. Quase sempre a iniciaçāo compreende "uma prova sacrificial ou mutilante que simboliza em segundo grau uma paixão divina"(12). O desterro tem, em Menina e moça, tal função e o sofrimento de cada personagem é a faixão que o purifica de uma vida mundana, abrindo-lhe as portas de um além que liberta o espirito.

\subsection{O lugar da iniciação.}

As imagens presentes em Menina e moça traduzem um desejo de proteção e de aconchego que nāo é outro senão o desejo de retornar ao seio materno. Assim, enquadram-se perfeitamente no que G. Durand chamou de Regime noturno do imaginário.

Alguns aspectos importantes devern ser analisados no que diz respeito ao lugar da iniciação. Primeiramente, a significação do monte remete-nos ao simbolismo do lugar sagrado. $O$ alio da montanha é o lugar das hierofanias. Aqui veio a menina em busca da ilu-

9 Mr p. 40

$10 \mathrm{MM}$ p. 48

11 MM p. 126

12 Cf. nota n. 5 , p. 351. 
minação que só de Deus poderia advir. Entretanto, ela não experiinenta nenhuma sensação de poder, tão comum ass que contemplam - mundo do alıo( $\left.{ }^{13}\right)$. E que, ao contrário do Regime diurno, aqui a ascensão tem outro sentido - é busca de luz divina para em seguida cescer às profundezas de si mesmo. E Durand quem nos ensina, ao analisar as imagens da intimidade, que "as escadas da casa descem sempre, e que subir zo sótão ou aos quartos é ainda descer ao coração do mistério" (14). Não é no alto do outeiro que a Menina medirará na sua vida através das estórias da Dama do Tempo Antigo, mas no aconchego do vale ao qual desceu. Devemos, pois, para compreender - lugar sagrado de Menina e moça, pensar no monte e nos "vales que o cingem em derredor" $\left({ }^{15}\right)$, o que coloca em evidência sua posição central, característica do lugar santo: "o que sacraliza antes de tudo um lugar é o seu fechamento" $\left({ }^{10}\right)$. A forma redonda que daí se deduz leva-nos à imagem uterina do microcosmo ou antes a uma cosmização [...] do arquétipo da intimidade feminina" $\left.{ }^{17}\right)$. Ao lado da imagem do ventre materno, porém, a forma do vale sugere ainda outra imagem: a do sepultro. Não há, na verdade, oposição. Dentro do processo cíclico de renovação cósmica, o lugar da morte é o lugar do renascimento. A morte é um rogressus ad uterum. $\left({ }^{18}\right)$.

Por outro lado, o vale é descrito como o centro paradisíaco, o lugar das delícias que "de árvores grandes e verdes ervas e deleitosas sombras cheio é" e "por onde um pequeno ribeiro de água"(19) corre. Podemos comparar esse cenário do do lugar santo segundo Durand: 'Et les meubles de ce lieu saint primitif, outre une source ou une étendue d'eau, sont l'arbre sacré, le poteau ou son doublet le bétyle ${ }^{\prime \prime}\left({ }^{20}\right)$. Eis uma passagem de Menina a moça que confirma a imagem do Paraiso:

13 BACHELARD, Gaston. La torro of les réveries de la volonté. 'La contemplation du hout des sommets nous donne la soudaine impression de la maitrise de lunivers." p. 385.

14 Cf. nota n.o 5, p. 280 . Os grifos são nossos.

15 MM p. 29

16 Cf. nata n.० 5, p. 281.

17 Ibidem. p. 281.

18 Nesse mesmo va'e morreu Belisa e nasceu Arima. Aí o mar rejeitou Avalor que renasce pars outra vida.

19 MM p. 31

20 Cf. noto n.o 5, p. 280 
Assim passava eu o tempo quando, umá das passadas pouco haveria, alevantando-me eu, vi a manhã como se erguia formosa estender-se graciosamente por enire os vales e deixar indo os altos, que já o Sol, alevantado até os peitos, vinha tomando posse nos outeiros, como quem se queria senhorear da Terra.

As doces aves, batendo as asas, andavam buscando umas as outras. Os pastores, tangendo as suas frautas e rodeados dos seus gados, começavam de assomar já pela cumeadas. do $\left({ }^{21}\right)$.

Para todos parecia que vinha aquele dia assim le-

Todavia, o coração da Menina não se identifica com essa natureza esplendorosa. Anies faz-rics ver o outro aspecto do vale, como - lugar da paixão:

Os meus cuidados, sós, vendo como vinha o seu contrário ao parece: podercso, reco.heram-se a mim, pondome ante os olhos para quanto prazer puciera aquele dia vir, se não fora tudo tão mudado! Por onde o que fazia alegre todas as cousas, a mim só teve causa de fazer triste. $\left({ }^{2}\right)$.

Com efeito, a alegria do mundo para aqueles que nele têm seu exilio é vã. Aquele paraiso, para os personagens de Bernardim, reveste-se de uma outra dimensāo: é o "vale de lágrimas", lugar de purificação.

\section{O VALE: A REPETIÇAOO DO CICLO}

A descida, como vimos, corresponde a uma desaprendizagem das verdades temporais à procura de outra mais profunda. Para tal, diante das dificuldades do caminho, o homem, sentindo-se só, necessita de proteção ou de um men'or( ${ }^{(23)}$, a fim de não cair. A Dama do Tempo Antigo parece ter essa função ao lado da Menina que, ao descer sozinha o monte, "no caminho, com a pressa que [.. ] levava, três ou qua'ro vezes (caiu)"("(-1). As estórias contadas são ensinamentos

$21 \mathrm{MM}$ p. 30

22 Ibidem

23 Cf. nota 5, p. 227

24 MM p. 3i. Ho caminho de sua paixz̃o Cristo caiu três vezes. 
que o mentor the transmite e que the servem de "couraças" contra as asperezas do mundo. São narrativas míticas que, repetindo as angústias da própria Menina através de outros personagens, representam uma vitória sobre o ciclo temporal e permitem um aprofundamento no processo de iniciação.

\subsection{A reduplicação das estórias}

As estórias narradas possuem todas um núcleo comum: são estórias de amores frustrados, como o da Menina. "O propósito do livro é relatar o que, visto e ouvido 'em coisas alheias', a fez reviver - seu próprio sofrimento"(25). Ora, trata-se aí de modelos arquetípicos que, por pertencerem aos tempos idos, tornaram-se estórias exemplares daquelas terras $\left({ }^{28}\right)$. No processo de iniciação da Menina, eias têm a função de mediado:as entre o começo e o fim do caminho da ascese. De Belisa a Arima, perfaz-se um percurso de purificação. Vemos, pois, nas três estórias narradas - a de Lamentor e Belisa, a de Bimarder e Aónia e a de Avalor e Arima - três etapas da estória daquela que, mais que qualquer um, conseguiu ultrapassar o rio da vida terrena. Com efeito, temos a aurora, o meio-dia e o crepúsculo cáa caminhada espiritual de Arima. No $10^{\circ}$ episódio, ela nasce; no $2 .^{\circ}$ cresce encerrada na casa do pai; no $3 .^{\circ}$, surge diante do mundo que, logo em seguida, abandona.

Marcadas pela determinação do destino, as vidas humanas seguem seu curso absurdo sem poder a ele se opor. O episódio do rouxinol é uma metáfora concreta do "sem-sentido da vida e da morte [...] traduzido por todos os episódios que formam o seguimento da novela: 0 amor do cavaleiro da ponte, o de Lamentor e Belisa, $\cdot 0$ de Binmarder e Aónia e o de Avalor e Arima" $\left.{ }^{27}\right)$. Realiza-se ciessa forma uma comunhão do natural e do humano: assim como o penedo interrompe o curso tranqüilo das águas, assim como a morte súbita interrompe o doce cantar do rouxinol, assim também os fados mudam os projetos dos homens. A morte de Belisa é tão absurda quanto a do pássaro, e o rio que aqui transporta o rouxinol morto recupe:a sua função mítica de rio infernal mais adiante repetida no episódio de Avalor:

25 Cf. nota n.o 1, p. 14.

26 Ibidem, p. 109. A presença de uma dama do tempo ANTIGO reforça o carb́ter mistico das estórias.

27 SARalva, Maria de Lourdes. Notas. In: RIBEIRO, Bernardim. Monina - moça. Publicaçōes Europa-América, 1975. p. 33 
Pela ribeira de um rio

que leva as águas ao mar

vai o triste de Avalor; $\left({ }^{28}\right)$

Quando o mar rejeita seu corpo por já estar ele "morto", a idéia da viagem para a outra vída através do rio dos mortos fica assim confirmada. $O$ absurdo das coisas reside na separaçāo de tudo aquilo cuja unidade traria o equilíbrio e a perfeiçāo. Há em Menina e moça um desejo de recuperar a unidade mítica pela reunião dos contrários: assim a natureza, assim os pares - homem/mulher - que, por força do destino, não se podem manter unidos. Fica claro, entretanto, e $\mathrm{H}$. Macedo no-lo mostra muito bem, que, com relaçāo aos homens, essa coincidentia oppositorum só se tornará possivel num plano metafísico. Os personagens de Bernardim Ribeiro, em sua maioria, buscam ansiosamente a sua parte complementar para, através do reencontro de animus e anima, recriar um ser perfeito, digamos assim, um andrógino espiritual. Vejamos o que diz $\mathrm{H}$. Macedo:

Se, na écloga, Jano e Joana são formas do mesmo nome, na Menina e moça a alma de Avalor é só metade, sendo - outia me:ade a própria Arima; e se a sepultura da alma de Franco está, na écloga, na "outra parte" personificada por Célia, na novela Lamentor chora a partida da sua própria alma quando Belisa morre: "para vós, senhora, estava ordenada uma sepultura em terra alheia, para a minha vida, duas. Mas a vossa terá o corpo e as minhas, - corpo e a alma". Claramente, das duas sepuliuras orćenadas para Lamentor, uma, a terra, é para o corpo, enquanto a outra, representada na próp:ia Belisa, é para a alma; assim, quando morrer, a terra será apenas a sua segunda sepultura, a do corpo. A morte de Belisa simboliza a saida da alma do corpo de Lamentor. Lamentor é explícito: "Não vos alembrou que era eu o que sem vós não havia de ser mais?" Sem Belisa ele não podia ser mais, mas e'a, no plano espirifual, continuaria a ser, sem ele. Assim, pa:a Bernardim, homens e mulheres representam niveis diferentes de qualidade espiritual( $\left.{ }^{29}\right)$.

3.2 A reduplicação do espaço

Os episódios narrados na novela possuem todos a mesma loca-

28 Cf. nota n. 1 . p. 153

29 Op. cit. p. $35-36$ 
lização. Foi no vale em que se acham a Menina e a Dama do Tempo Antigo que todas as estórias se passaram. Para lá foi levado Avalor pela força das ág'uas e Arima de regresso à casa do pai.

Parece que a sua desaventura de Avalor, que assim the chamo eu, deu com ele para aquela banda para onde era levada a senhora Arima, que esta nossa seria en:ão. $\left({ }^{30}\right)$

Assim, fecha-se a novela de forma circular, o que vem corroborar o esquema cíclico das estórias que são, estruiuralmente, repetiçōes da estória de amor da Menina que acabou por se não contar.

Helder Macedo alude a uma possibilidade de identificação da Menina com Aónia e cita o freixo como um elemento recorrente no episódio de Bimarder e na narrativa inicial da Menina. Ora, isso confirma mais uma vez a unidade espacial da novela cujo cenário é o vale. "L'espace secré possède ce remarquable pouvoir d'être multiplié indéfiniment" ${ }^{31}$ ), diz G. Duränd. Embora esta afirmaçāo apliquese à diversidade de templos e lugaies divinizados, podemos nela enquadrar o espaço sagrado de Menina e moça. Sua multiplicação não se deu do ponto de vista de um deslocamento espacial - dai, sua unidade - mas no retornar cíclico do tempo. As estórias dos três cavaleiros reafualizaram, cada uma em seu momento, o lugar sagrado da novela.

Processa-se dessa forma uma superposição espácio-temporal pelo reencontro das estórias do tempo antigo com o presente da Menina. O espaço, por seus poderes sagrados, interrompe a fuga inexorável do tempo, obrigando-a a recomeçar sempre naqueles limites um mesmo ciclo. Assim, espacializa-se o tempo, numa ambição fundamental de dominar o devir.

\section{CONCLUSAOO}

A sombra das tuas vestes

Ficou entre nós na Sorte.

Não 'stás morto, entre ciprestes.

Neófito, não há morte.

\section{Fernando Pessoa}

$30 \mathrm{MM}$ p. 155

31 Cf. nota n. ${ }^{\circ}$ 5, p. 284

PESSOA, Fernando. "Iniciação". In: ---. Obra Poótica. Rio de Janeiro, Agullar, 1969, p. 162. 
O gesto de descida que caracte:izou a atitude da narradora inicial da novela traduz o desejo obstinado de um tesouro, de um repouso, de urra verdade que está para além da vida. A imagem do vale confirma esse gesto que é, em suma, um mergulhar profundo na intimidade substamcial à procura de algo oculto. A descida para - vale é, em termos espirituais, o aprofundamento de si mesmo que loda meditação torna possivel. Ali, ao "aguardar a sua derradeira hora", a Menina decide escrever "as cousas que (viu) e (ouviu)"(3z), para melhor se conhecer "pois não havia de escrever para ninguém senão para (ela) só"( ${ }^{33}$ ). Alravés das estórias, realiza-se a puigação das almas de quem as conta e de quem as ouve.

A estrutura da obra, pela sintaxe de reduplicação, reforça o sentido da novela que, existindo como obra de arte, concretiza a repetisão simbólica do ciclo temporal, a cada releitura.

Ao nivel de sua significação esotérica, a novela, acentuando o dualismo gnóstico entre matéria e espírito, insiste na vitória do esplrito que, representado pelo destino de Avalor, após a morte do corpo atnge a união com Deus.

32 MM p. 25

33 loidem, p. 26

\section{BIBLIOGRAFIA}

5.T BAChelard, G. L'qay at les river. Poris, José Corti, 1943.

5.2 -_- L'air ct !es songes. Pàris, J. Corti, 1943.

5.3 -_- L. La poótique de l'espace. Paris, PUF, 1972.

5.4 -__- La psychunalyse du feu. Paris, Gallimard, 1969.

5.5 - _-_. La terre ct les reveries du repos. Paris, J. Corti, 1948.

5.0 _-__- La terre et les rôveries do to volonté. Paris, J. Corti, 1948.

5.7 DURAND, G. Les strutfures ar.thropoiogiques de l'imaginaire. Paris, Bordas, 1969.

5.8 BlBLIA SAGPADA. Pe. António Charbel, ccord. trad., São Paulo, Editora Abril, 1965.

5.9 BURLAND, C.A. Le savoir cachó des alchimistes. Paris, Robert lafont, 1969.

5.10 ELIADE, M. Aspects du mythe. Paris, Gullimard, 1969.

5.11 - - - Le chamanisme of les tachniqugs archaiques d'extase. Paris, Payot, 1949.

5 12 - - - Ls mytha de iélernel retour. Paris, Gallimard, 1969.

5.13 -_- Neythes, rêvcs et mystórec. Paris, Gallimard, 1972.

5.14 _-_. Trzifé d'histoire des religions. Paris, Payot, 1977.

5.15 HUTIN, E. L'alchimic. 4. ed. Paris, Puf, 1971. (Col. Que sais-je?, 506).

5.16 MACEDO, He!der. Do significado oculto da Menina - Moça. Moraes Editores, Lip. boa, 1977.

5.17 PESSOA, Fernando. Obra poettica. 3 ed. Rio de Janeiro, Aguilar, 1969.

5.18 RIBEIRO, Be:nardim. Monir.s - meşa. Públicaçōes Europa-América, 1975. 
5.19 SCHOLEM, Gersiom. A mistica judalea. Säo Paulo, Perapectiva, 1972.

5.20 TONDRIAU, Julien. L'occultisme. Verviers, Gérard e c.; 1964.

\section{RESUMO}

O outor apresenta um estudo das imagens do romance Menina - Moge do autor português Bernardim Ribeiro, a partir da teoria de Gilbert Durant om Los Structures Anthropolegiques de l'imaginaire. O romance mostra entäo, no sua estrutura circular, todas as etapas de um processo de inieieçäo: \& prove sacrificial, a deseida cos abir mos do ser, o triunfo do espirito.

\section{RESUME}

L'auteur présente une blude des images du roman Menina - moçe do l'outeur portugais Bernardim Ribeiro, a partir de la thérie de Gilbert Durand dane Les Strue tures Anshropologiquas de l'Imaginaire. Le roman nous montre alors, dons sa structure circulaire, toutes les étapes d'un processus d'initiation: l'éprouve sacrificieilo, la doscente aux abismes de l'estre et le triomphe de l'esprit. 